\title{
EXPECTATIONS, RIVALRIES, AND CIVIL WAR DURATION
}

\section{Seden Akcinaroglu Elizabeth Radziszewski}

\author{
Department of Political Science, University of Illinois, \\ Urbana-Champaign, IL, USA
}

\begin{abstract}
What role have states involved in a rivalry with another state played in shaping the dynamics of their rival's civil wars? How can the existence of an interstate rival affect rebel calculations whether to continue fighting or stop the violence and negotiate? And to what extent does rival intervention differ in its impact on civil war duration from interventions by other actors? This paper argues that the existence of an interstate rival can prolong conflict even when actual aid has not been granted. The mere expectation of assistance from a rival, whether in the form of military intervention or provision of funds, can deter rebels from seeking settlement and motivate fighting at least for some time until resources are depleted. We estimate conditions under which interstate rivals are most likely to intervene in civil wars. We then argue that conditions conducive to rival intervention serve as a base upon which rebels form their expectations of forthcoming aid. We use predicted probabilities from the probit and the multinomial logit model to calculate expectations of rival intervention. Finally, using duration analysis we show that expectations of rival intervention can substantially prolong civil wars especially in a transparent society.
\end{abstract}

Keywords: interstate rivalries, civil wars, expectations, duration, intervention

In a time when civil wars span for decades, funding from foreign states acting as rivals of the central government has been critical in sustaining rebel activity and making settlement harder. Violence in Bangladesh,

The authors would like to thank Bill Bernhard, Jon Dicicco, Paul Diehl, Florin Fesnic, Christina Furtado, Brian Gaines, Robert Pahre, Patrick Regan, Ionas Rus, Ahmed Salem, Tom Walker, and anonymous reviewers for their useful comments and suggestions.

Address correspondence to Elizabeth Radziszewski, Dept. of Political Science, University of Illinois, Urbana-Champaign, IL 61802, USA 
Israel, and Cambodia demonstrate that outside support from interstate rivals is often linked with longer civil wars.

To what extent does an interstate rival affect the duration of its enemy's civil war? How do rebels form expectations of assistance from an interstate rival, and how do such expectations matter in conflict dynamics? Finally, to what degree do interventions involving rivals differ in their impact on the war's duration from nonrival interventions?

Understanding these questions is critical in explaining how interstate militarized competitions can influence the duration of internal violence, a linkage which remains undeveloped in the study of civil wars. Previous research on civil war duration has focused extensively on domestic factors including, commitment problems, ethnic fragmentation, and access to lootable resources (for example, Fearon, 2002; Collier and Hoeffler, 2000; Ross, 2003; Elbadawi and Sambanis, 2000; Walter, 2002). The international dimension, usually involving interventions, analyzes foreign involvement as a strategy of conflict management, but not as one designed to prolong conflict resolution (for example, Regan, 2002; Prunier, 1995; Walter and Snyder, 1999). Although we know more about the impact of interventions on altering capabilities of the warring parties, little empirical research exists on the kinds of states that intervene and on their intentions.

By introducing external rivalries into the study of civil war, we expand current theoretical insights by focusing on the interests and characteristics of specific types of intervening actors - the rivals - and their subsequent effect on conflict duration. We depart from the research that examines the impact of interventions mostly after their occurrence, and show instead how the existence of an interstate rival can prolong the conflict even when actual involvement has never materialized. The mere expectation of possible financial assistance from the rival, we argue, can deter rebels from seeking settlement. Using predicted probabilities, we find that enduring and intense rivalries send a credible signal to the rebels that intervention is possible, thereby increasing fighting morale and prolonging the war's duration. Moreover, we claim that the level of transparency in the society and the type of intervention that rebels anticipate are likely to affect differently their propensity to sustain the conflict.

In addition to a theoretical contribution, the rivalry approach to civil wars offers policy suggestions that could render diplomatic efforts at conflict settlement more successful. Our findings show that interventions involving interstate rivals, as opposed to interventions without rivals, are consistently related to prolonged fighting. This implies that effective mediation efforts should not only address the needs of the government and the rebels in the conflict but simultaneously focus on improving the relationship between external rival and central government of the state torn by civil war. 
This paper has three aims. First, it explores the theoretical link between interstate rivalries and civil wars by focusing on mechanisms through which rivals can influence the war's duration. Second, it uses a probit model to show how expectations of rival assistance can be formed. Third, it relies on duration analysis to test several hypotheses about expectations' impact on the war's duration. The paper concludes with implications for future research.

\section{EXTERNAL INTERVENTION, RIVALRIES, AND CIVIL WAR DURATION}

To explore the linkage between internal conflict and international factors, studies focus extensively on the impact of interventions on conflict duration. Some suggest that interventions terminate conflict by decisively altering the balance of power between the warring parties making a compromise or an outright victory a likely outcome (Licklider, 1993; Walter, 1997; Rasler, 1983). At the same time, foreign intervention is also associated with longer conflict when it is not strong enough to culminate in decisive victory. Numerous empirical studies support this argument (for example, Pearson, 1974; Mason, Weingarten, and Fett, 1999; Elbadawi and Sambanis, 2000; Regan, 1998, 2002).

The intervention literature, however, is limited in examining who intervenes, under which conditions, and with what consequences. Looking at timing and targets is one way to approach the puzzle of intervention. Regan (2002), for example, finds that when intervention occurs in the early stages of the conflict, it is associated with shorter wars. Given that war is costly, early settlement might be an attractive option to the parties if the payoff from the settlement is expected to resemble rewards, had later victory been achieved. Focusing on the target of intervention, it appears that foreign assistance to the opposition is related to longer wars (Bach-Lindsay and Enterline, 2000; Elbadawi and Sambanis 2000), while aiding the government leads to termination of violence (Regan, 2002).

While empirical results on the timing and target of intervention help to uncover why outside intervention is associated with longer violence in one instance and settlement in another, present theoretical framework is limited in exploring the motives behind the interventions - a concept critical in understanding how foreign involvement alters duration of conflict. When intervention prolongs civil wars, most scholars rarely consider this an intentional development. Instead they see it as a result of mismanaged policy. The usual culprit here is the assumption that interveners are regional/global hegemons or IOs, but not states engaged in a rivalry with their war-torn foes.

Focusing on rivalry is one way of bringing a new dimension to the way we think about interventions, strategic behavior, and civil war duration. While 
motivations for intervention vary across actors, states engaged in interstate rivalry with the country torn by civil violence have a particular interest in intervening and manipulating the conflict to their advantage as doing so increases their own position in the international system particularly with respect to their rival (Snidal, 1993). When a state is experiencing civil war, its external rival is thus likely to assist rebels to weaken the central government ${ }^{1}$ and change the balance of power in its favor (Wirsing, 1994).

Previous research assumes that material aid is the only tangible source of help required to prolong fighting. While we generally share this consensus, we argue that even when actual assistance has not been supplied, expectation of aid can prevent settlement. Expectations can be a particularly important source of morale to the opposition in cases when the central government has an interstate rival who has an interest in destabilizing the government. For example, insurgents in Poland revolted against Nazi occupation in 1944 and continued their struggle because they expected that the USSR would provide them with aid to facilitate the destruction of the common enemy (D'Este, 2004).

Interstate rivalry signals to the rebels a strong possibility of foreign involvement. Certain characteristics of the rivalry create strong expectations of intervention and affect rebel resolve to fight. For example, a rivalry low in duration and intensity might lack the gravity of tensions to motivate rival involvement in a potentially costly war. In such a case, the rebels would be less likely to anticipate intervention and more destined to rely on their own capabilities in deciding whether or not to fight.

We can express the link between expectations of rival intervention and extended fighting more formally in a simple game theoretic model of civil war duration.

The game depicted in Figure 1 is a finite incomplete information game. At the start of the game, the rebel group and the government decide simultaneously whether or not to initiate the war. If both choose to fight, the game is carried to the second decision node. The rival then chooses whether or not to intervene based on the type of rivalry - that is depending on certain rivalry characteristics that can create different incentives for intervention. The type of the rival is only revealed to itself meaning that only the rival has full information about its own incentives to intervene. The probability associated with each type, where $\mathrm{p}$ denotes a probability of being type 1 and $1-p$ denotes the probability of being type 2 , however, is common information allowing the rebel group to form some beliefs about the type of the rival and compute its expected payoffs based

\footnotetext{
${ }^{1}$ Our focus throughout the paper is on rival intervention on the side of the opposition. Although in some instances rivals assist the central government, these cases are few and not at odds with strategic calculations of the rival. We address them in detail in footnote number 14.
} 


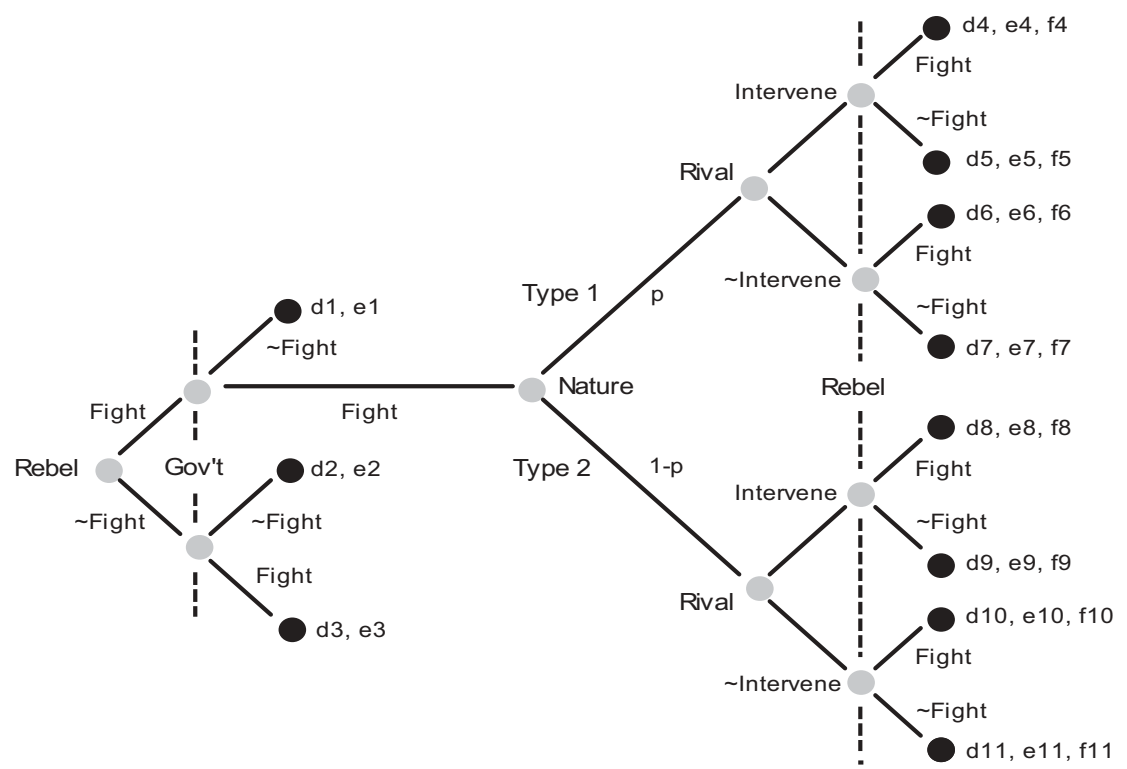

Figure 1. A Model of Rival Intervention and War. ${ }^{3}$

on the complete profile of the rival's types. The rebels then decide whether to fight or end the war. The normal form of the last subgame is depicted below and shows the existence of different Nash equilibrium based on payoffs and beliefs about types of rivals.

To understand the role of beliefs in yielding different equilibrium, we consider in detail one specific case where each type is associated with a strictly dominant strategy, e.g, type 1 rival always intervenes ( $\mathrm{f} 4>\mathrm{f} 6$ and $\mathrm{f} 5>\mathrm{f} 7$ ) and type 2 rival never intervenes ( $110>\mathrm{f} 8$ and $\mathrm{f} 11>\mathrm{f} 9$ ). The rebel group then continues fighting if its expected utility from fighting exceeds its expected utility from ending the war, that is when its beliefs

Table 1.

\begin{tabular}{|c|c|c|c|c|}
\hline Rebel/Rival & $\begin{array}{l}\text { Intervene } \\
\text { Intervene }^{2}\end{array}$ & $\begin{array}{l}\text { Intervene } \\
\text { Intervene }\end{array}$ & $\begin{array}{l}\text { 〜ntervene } \\
\text { Intervene }\end{array}$ & 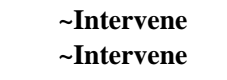 \\
\hline Fight & $\begin{array}{l}p(d 4)+(1-p) d 8 \\
p(f 4)+(1-p) f 8\end{array}$ & $\begin{array}{l}p(d 4)+(1-p) d 10 \\
p(f 4)+(1-p) f 10\end{array}$ & $\begin{array}{l}p(d 6)+(1-p) d 8 \\
p(f 6)+(1-p) f 8\end{array}$ & $\begin{array}{l}p(d 6)+(1-p) d 10 \\
p(f 6)+(1-p) f 10\end{array}$ \\
\hline$\sim$ Fight & $\begin{array}{l}\mathrm{p}(\mathrm{d} 5)+(1-\mathrm{p}) \mathrm{d} 9, \\
\mathrm{p}(\mathrm{f5}),(1-\mathrm{p}) \mathrm{f} 9\end{array}$ & $\begin{array}{l}p(d 5)+(1-p) d 11 \\
p(f 5)+(1-p) f 11\end{array}$ & $\begin{array}{l}\mathrm{p}(\mathrm{d} 7)+(1-\mathrm{p}) \mathrm{d} 9 \\
\mathrm{p}(\mathrm{f} 7)+(1-\mathrm{p}) \mathrm{f} 9\end{array}$ & $\begin{array}{l}\mathrm{p}(\mathrm{d} 7)+(1-\mathrm{p}) \mathrm{d} 11 \\
\mathrm{p}(\mathrm{f} 7)+(1-\mathrm{p}) \mathrm{f} 11\end{array}$ \\
\hline
\end{tabular}

${ }^{2}$ The first strategy is associated with type 1 , and the second strategy is associated with type 2 .

${ }^{3}$ The rebels' payoff is denoted as " $d$," the government's as "e," and the rival's as "f." 
about the rival's type satisfy p/(1-p)> (d11-d10)/ (d4-d5). In this case (Fight, Fight, Fight; Intervene Intervene) is the subgame perfect equilibrium of the game if $\mathrm{p}(\mathrm{d} 4)+(1-\mathrm{p}) \mathrm{d} 10>\mathrm{d} 3$ and $\mathrm{p}(\mathrm{e} 4)+(1-\mathrm{p}) \mathrm{e} 10>\mathrm{e} 1{ }^{4}$ Although in this model we considered two rival types with two different rivalry characteristics, we can easily extend this argument to a more general setting, where types may be continuous, e.g., rivals with many different rivalry characteristics exist. If we assume each rival has a cost of intervention, $\mathrm{Q}$ uniformly distributed between 0 and 1 , then only rivals with types above a certain threshold $\mathrm{Q}^{*}$ would intervene with a probability of $1-\mathrm{Q}^{*}$. Rebels would then form their expected payoffs based on such threshold. In the subsequent section, we specifically model which characteristics of the rivalry determine rival intervention, and in turn rebel expectations.

\section{MODEL OF EXPECTATIONS OF RIVAL INTERVENTION: CONCEPTS, DATA AND RESULTS}

Before assessing the impact of expectations of rival intervention on civil war duration, we need to first measure expectations. We model rival intervention as a function of rival characteristics and factors exogenous to the rival such as conflict type and the size of the initial rebel force. Predicted probabilities from the probit model then serve as proxies for expectations, which yield a continuous and interpretable indicator.

\section{Conceptualization and data}

We relied on Patrick Regan's (2000) data and followed his definition of intrastate conflict as armed combat between groups within a state that leads to at least 200 fatalities. When discussing rivalry we are referring to a pair of states with at least two militarized disputes over a period of minimum two years. This definition allows us to distinguish between rivalries whose history and frequency of interaction is likely to affect their behavior towards each other, such as a possibility of intervention, and those, very isolated incidents of conflict, which are short of rivalries. We rely on Diehl and Goertz (2000) for all rivalry data. We found 103 cases of civil wars, including 60 coinciding with rivalries and 28 ongoing conflicts as of $1992 .{ }^{5}$

\footnotetext{
${ }^{4}$ This is the case where both the government and the rebel group simultaneously decide to fight at the initial stage of the game.

${ }^{5}$ Although Patrick Regan's (2000) dataset includes 125 cases of civil wars until 1992, the data we employ is slightly reduced as we have merged 22 of the overlapping wars for the same state. Merging these cases facilitates the analysis since we assume here that decisions about intervention are likely to be formed based on the extent of rivalry that exists between the outside state and the central government rather than on the nature of the rebels, unless their ideology is completely at odds with that of the rival state.
} 
Finally, we define intervention as the use of one state's resources to influence the internal conflict of another state. Intervention is either military and associated with provision of personnel, troops, supplies, and intelligence or economic when it involves granting and withdrawing of aid.

\section{Independent Variables}

\section{Rival Characteristics}

Rivalry Severity: We estimate the severity of rivalry between state A and a civil war country by calculating the mean severity of their militarized disputes before and during the war. Based on a 0 200 scale, rival severity in our cases ranges from a low score of 19, which indicates tensions limited to threats, to a high value of 164 indicating that states have fought at least one war with each other.

Rivalry Duration: Rivalries' length is measured in months and lasts on average 17 years.

Rival Constraint: This variable measures the degree to which the rival of the civil war country is constrained by the number of rivals it has, which might affect its decision about intervention. Our data reflects the number of rivals that each rival of the civil war country had before and during the outbreak of the conflict.

Government Rivals: The variable refers to the total number of rivals the civil war country has. The more rivals the country has the more likely that one of them will intervene.

Contiguity: Probability of intervention should increase when states share a border. Contiguity facilitates transportation of military supplies to the rebels and improves exchange of information. We assigned a value of one to rivalries between neighbors, and a value of zero for noncontiguous cases.

Internal Characteristics of the Conflict

Casualty: Previous work by Regan (2000) has shown that successful interventions are associated with low-casualty conflicts because "safer" war environments are selected by intervening actors due to lower costs of involvement. We rely on Regan (2000) for the number of casualties and measure the variable in ten thousands.

Conflict Type: Some conflicts are more prone to invite intervention than others. Ethnic conflicts, for example, involve multiple identities that can be constructed and discarded making it 
harder to distinguish participating groups and their goals (Kaufmann, 1996). It then follows that it might be less costly to intervene in nonethnic conflicts where issues might be more transparent. Dummy variables distinguish between religious, ethnic, and ideological conflicts (Regan, 2000). ${ }^{6}$

Opposition capability: We measure the opposition's capability by estimating the number of rebels participating in the combat against the government. Most of our data comes from Regan (2000) and journalistic reports. Capability is measured in ten thousands.

Government capability: Our primary focus here is on military manpower as a crude estimation of government's ability to challenge the rebels. We use COW's data and measure the variable in ten thousands.

Balance of Capabilities: It is the ratio between government and opposition forces.

\section{Dependent Variable}

\section{Rival Intervention}

To understand how rebels form expectations of rival intervention, we need to determine which factors yield the highest probability of rival intervention. Our data ranges from 1944 until 1992 and includes a total of 60 civil war cases coinciding with rivalries. ${ }^{7}$ Since some civil war states have more than one rival, we have a total of 160 observations that account for multiple rivalries for the same war. Intervention is coded one if it involves both rivals and nonrivals, and zero if it is absent. We recognize potential limitation in coding rivals and nonrivals together since we cannot precisely differentiate which portion of expectations is formed based on prospects of intervention by the rival, the other intervener, or both. Still, such coding might be justified given the very limited number of cases with rival state as the only intervening actor $(\mathrm{N}=7),{ }^{8}$ making it

\footnotetext{
${ }^{6}$ Conflict type considers the actors and the broader issues of the conflict. It could have a substantial impact on the costs of intervention, and hence on the rival's decision whether or not to intervene. Rebel ideology, which is part of the issues in a conflict, therefore, is also likely to affect decisions about intervention. However, as we argued in an earlier footnote rebel ideology will be of lesser consideration to the rival when deciding whose side to support. Given that rivals have a strategic interest in destabilizing the central government, they are most likely to aid the rebels regardless of their ideology unless it is completely at odds with the rival's interests.

${ }^{7} \mathrm{~A}$ complete list of civil wars coinciding with rivalries is listed in Appendix 1.

${ }^{8}$ Rival and nonrival interventions together account for 32 cases, while interventions by nonrivals alone consist of 44 cases. Only seven cases represent interventions by rivals alone.
} 
difficult to arrive at separate inferences on the rival category alone. One of the challenges we face is to isolate the impact of rival vs. nonrival state on the war's duration. We address this issue in the duration analysis in the subsequent sections.

\section{Discussion of Results}

Table 2 presents the results from the probit model of rival intervention. The model shows which rival characteristics might motivate intervention. Specifically, we find that a rival is likely to intervene when the opposition is stronger and the government weaker. ${ }^{9}$ This suggests that a rival would be reluctant to support rebels with a very limited ability to inflict damage on the government choosing instead to intervene when the opposition has tangible chances of mounting a challenge.

The model also demonstrates a positive and significant relationship between rivalry duration and intervention. As expected, the longer the rivalry the more likely that the rival has an interest in influencing its foe's internal dynamics either because of its own domestic pressures or because it might seek to reduce chances of future conflicts that are often expected when rivals share a history of tensions.

The empirical results from the composite variable show that a rival will be more willing to intervene when it has a low number of rivals and its rivalry with the civil war country is both highly severe and enduring. We can see that severity alone does not improve our understanding of when intervention occurs. Instead it matters when interacted with rivalry duration and rival constraint. The finding from the composite variable demonstrates that limited constraints on the rival might reduce costs involved with offsetting other rivalries and increase chances of intervention when the rivalry of interest is both severe and enduring. ${ }^{10}$

The most surprising finding from the model is the positive sign of the estimated coefficient for rival constraint alone, suggesting that a rival highly constrained by other rivalries is more likely to intervene. The positive sign in the coefficient runs contradictory to the sign of the composite variable that showed a decline in intervention with an increase in rival constraints. The puzzle is the positive relationship between rival constraint and intervention on the one hand, and a negative relationship when

\footnotetext{
${ }^{9}$ Model one presents results when government and opposition capabilities are estimated in the equation, while model two incorporates an alternative measure of capabilities-the ratio of government and opposition capabilities. We find that both measures capture the significance of the balance of capabilities between the government and the rebels on a decision to intervene.

${ }^{10}$ For example, in 1990s Pakistan increased its support to Kashmiri insurgents after it ended a conflict with its rival Afghanistan and had "idle soldiers" that could be used to fight another enduring and severe rival (Schofield, 2003).
} 


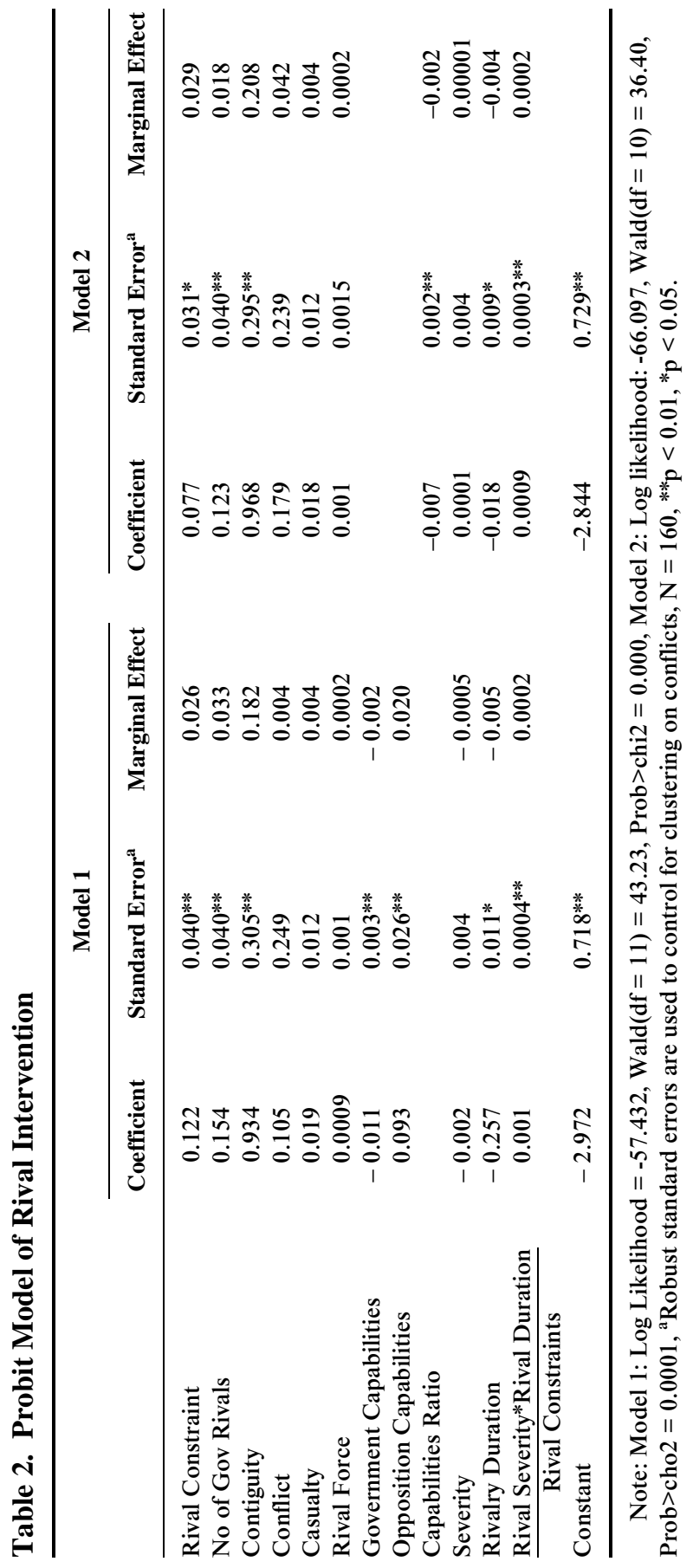


rival constraint is part of the composite variable along with rival intensity and duration. We conclude the following: It is reasonable to assume that even though rivals might be engaged in multiple rivalries as they are contemplating intervention in one of their enemy's civil war, those are low intensity rivalries that do not impose a negative constraint on the decision to intervene. Negative Pearson's correlation between rival constraint and intensity of rivalries supports our explanation. The inclusion of the composite variable further specifies that if a rival is simultaneously involved in multiple rivalries, it is much more likely to intervene in the civil war of one of its foes if it shares an enduring and highly intense rivalry with that particular enemy but has nonthreatening rivalries with others.

The estimated coefficient for the number of government rivals has the expected direction and is statistically significant. It is probably the case that the presence of multiple rivals of the civil war country increases the rival's involvement in conflict because multilateral intervention is less costly. We expect rivals to anticipate that other rival states will also intervene and pool the resources. ${ }^{11}$

\section{MODEL OF CIVIL WAR DURATION: HYPOTHESES, DATA AND RESULTS}

\section{Hypotheses}

So far we have demonstrated that specific rival characteristics including material constraints, the duration and intensity of rivalry, as well as contiguity help estimate which types of states are likely to intervene and assist the rebels. We can now begin to understand how expectations of rival intervention can influence the war's duration. To incorporate expectations into our model of duration we assume that the probability of intervention is unknown to the rebels and the government. Even though certain factors, such as specific characteristics of the rivalry between state A and their country's central government, might lead the rebels to believe that intervention can occur, a degree of uncertainty will prevent the opposition to judge precisely whether assistance will be granted. The game theoretic model has shown that rebels would expect a rival with the cost $\mathrm{Q}_{\mathrm{i}}$ to intervene if $\mathrm{Q}_{\mathrm{i}}>\mathrm{Q}^{*}$. Expectations of intervention would mean additional fighting force for the rebel and possibility of prolonged war. The rebels

\footnotetext{
${ }^{11}$ We turn to a brief discussion of the control variables. Despite Regan's (2000) findings on the importance of certain features inherent to the conflict itself, we find some contrary evidence. Both the number of casualties in the conflict and the type of civil war are not significant. This might not be surprising given that we focus on factors that explain rival intervention as opposed to any type of intervention, which makes our set of cases more restricted than Regan's. As expected, contiguity is statistically significant.
} 
would continue fighting if their expected force, (1-Q*)(rival force)+ (rebel force) exceeded government force. Thus, a low threshold of $\mathrm{Q}^{*}$, which implies a high probability of intervention may increase the resolve of the rebels to continue fighting even in a situation where their force prevents them from effectively challenging the government at a time when aid has not arrived. Therefore, we can conclude:

Hypothesis 1: The greater the expectations of rival assistance, the higher the rebel resolve to prolong the war even when actual aid has not been provided.

Yet many interventions in civil wars involve multiple actors including rival and nonrival states with unique goals that have implications for the conflict's duration. Interventions involving rivals, for example, are more likely to prolong the war as it is strategically in the rival's interest to impose costs on its foethe central government. By providing assistance to rebels, and therefore prolonging the conflict, the rival challenges the government by forcing it to devote funds to its own domestic problems instead of focusing on interstate rivalry.

While all states seek quick and successful outcome in their intervening strategy (Regan, 2000), the costs of long-term aid to rebels are likely to differ depending on whether an intervening state is a rival or not. Nonrival states are likely to pursue more cautious policies than rivals and aim for termination of violence. Indeed, interventions by nonrivals are often designed to resolve conflicts (Walter and Snyder, 1999) and if, for some reason, they do prolong the war, it is usually a result of mismanaged policy that has little to do with localized rivalries between the civil-war state and another actor. A nonrival state, particularly a democratic one, would be reluctant to engage in a conflict where the prospect of conflict resolution is dim because such policy would entail political costs for the leadership. On the contrary, domestic costs for rivals are much lower because the public and the elite are usually accustomed to negative images of the enemy that facilitate support for long-term intervention. Therefore, the rival need not always aim for termination of violence as a strategy of intervention. We conclude:

Hypothesis 2: Interventions by nonrivals alone are more likely to resolve the conflict, and therefore decrease the duration of civil wars.

The extent to which rebels base their fighting on hopes of assistance from an interstate rival depends not only on the rivalry's 
characteristics but also on the degree to which rebels recognize the importance of those traits. In a world of incomplete information, rebels face uncertainty about possible intervention particularly if they have minimal knowledge about the rival's relationship with the central government and receive limited signals about the prospects of aid. While sophisticated groups develop transnational networks that facilitate transparency of information, other movements are less capable of deciphering the nature of rivalry and its connection with their cause. Thus, when a rival state signals to the central government its support for the rebels by making public threats, it sends a signal that could provide strong basis for expectations of assistance. On the contrary, if the rival signals its policy of neutrality, then expectations of aid are likely to decline. The degree to which rebels receive signals of possible aid will depend on the level of transparency in the state or the existence of common knowledge between actors about information concerning policies (Winkler, 2002). In a society where independent journalists disseminate information about government dealings with other states, rebels have a greater propensity for updating and forming accurate expectations of aid. We can conclude:

Hypothesis 3a: High expectations formed in a transparent environment will increase certainty of interstate rival's assistance and, in turn, lead to longer wars.

Hypothesis 3b: Low expectations formed in a transparent environment will decrease certainty of assistance and contribute to shorter wars.

The impact of expectations on rebel resolve is likely to change through time. That is, the incentive to prolong the war will be the greatest at the initial stages of the conflict, as it is at that time that rebels anticipate assistance, and slowly decrease through time. In instances when intervention occurs in later stages of the war, we should expect rebels to update their expectations of future assistance. At that point expectations will be at least as high as they were at the initial phase of the conflict. Therefore:

Hypothesis 4: Through time, expectations of rival intervention will have a diminishing impact on civil war duration, unless an intervention occurs, in which case, expectations will be high again and fighting will continue.

We also need to recognize that the extent to which the rebels can sustain their struggle might depend on the type of aid they hope to receive. In cases when rebels expect military assistance from the 
rival, their fighting resolve will be high prior to intervention. Once decisive military intervention occurs and is strong enough to offset the government, conflict might terminate. We should then see a situation where high expectations prior to military intervention are associated with shorter wars. Yet, we know that not all military interventions by rivals are successful. We expect that after a military intervention fails to achieve a desired outcome for the rebel cause, expectations of future assistance are likely to be low leading to decline in rebel resolve. While rivals might still have a higher domestic tolerance for engaging in a costly military venture in their enemy's conflict than nonrivals, failure to substantially alter the balance of power might create an incentive for withdrawal. After some point, even rivals might see the costs as too high.

Expectations of economic aid, however, are likely to be high for a longer period of time because such intervention is usually less costly than military involvement. Even if the rebels are unable to decisively challenge the government, it might still be in the interest of the rival to provide funding for small-scale operations that weaken the government. Consequently, the rebels should have a fairly high expectation of aid that, in turn, should decrease their incentive for settlement.

Finally, expectations of both military and economic aid suggest a rather strong possibility of rebel success in the conflict. Prospects of military and economic aid not only imply large amounts of assistance, but also a greater certainty and time commitment from aid suppliers. For example, rebels might infer that even if military assistance ends, they can still receive economic support for an extensive period of time. In such cases, rebel resolve should be high and deter the group from laying down the arms. We can thus propose:

Hypothesis 5a: Expectations of economic assistance are likely to prolong civil wars.

Hypothesis $5 b$ : Expectations of military intervention are likely to wane in the long run leading to shorter wars.

Hypothesis 5c: Expectations of combined military and economic aid are likely to increase rebel prospects of victory and prolong their desire for fighting.

\section{Data and Duration Model}

We employ the duration model to test the impact of expectations on civil war's length. Event history or duration models are longitudinal observations indicating the duration of time spent in a certain state before and event occurs (Box-Steffensmeier and Jones, 2003). The failure time in survival models is defined as the time in which the event of interest-such as 
war termination-occurs. Critical in understanding when the failure will occur and how each covariate is going to contribute to the phenomenon through time, the hazard rate denotes the probability of experiencing an event in a small time interval given that the unit has survived until the beginning of that interval. Our analysis is based on the Cox Proportional Model-a semi-parametric model analyzing survival data. ${ }^{12}$

\section{Data and Conceptualization}

We rely on Regan's data (2000) on civil wars and on Diehl and Goertz's (2000) rivalry data. Analysis spans from 1946-1992 and includes 103 cases of wars. Concepts of interstate conflict and rivalry are the same as in our model of rival intervention.

\section{Independent Variables}

\section{Expectations of Rival Intervention}

We use predicted probabilities from the probit model of rival intervention as proxies for expectations. ${ }^{13}$ Our variable yields a continuous and interpretable indicator. The sample of cases used to arrive at the expectations variable included 60 cases of civil war countries with 160 interstate rivals coinciding with the timing of the war. Since we have multiple rivalries for some wars, we take the maximum predicted probability for intervention as the expectations value for the particular war. ${ }^{14}$ Taking the maximum value is appropriate because the rebels will anticipate aid from the state that is the most likely to intervene.

\footnotetext{
${ }^{12}$ The hazard rate can be computed in the following manner: $h(t)=f(t) / S(t)$. The hazard rate for the $\mathrm{jth}$ individual is given by $\mathrm{hj}(\mathrm{t})=\mathrm{ho}(\mathrm{t}) \exp (. . \mathrm{x})$, where $\mathrm{h} 0(\mathrm{t})$ denotes the baseline hazards function and .. $\mathrm{x}$, the covariates. We prefer to use a Cox Proportional Model rather than other parametric models such as Weibull and Exponential because we are cautious in making distributional assumptions for time dependence.

${ }^{13} \mathrm{We}$ rely on studies in political economy that derived predicted probabilities as measures for expectations of leadership exit (Leblang, 2002).

${ }^{14}$ While in this paper we are interested only in rebel expectations, we recognize that sometimes rivals of the central government might intervene and support the government when rebel ideology is extreme, and the rival sees it as strategically more threatening than the status quo. We find seven instances in which an interstate rival intervened to support the government and not the rebels. We conclude: First, we argue that even when rebel ideology is opposed to that of the rival state, rebels can still form expectations of assistance albeit limited those might be, if the rival has a highly intense history of disputes with the central government. Second, even if we assume that rival intervened on the side of the government and rebel expectations of assistance are equal to zero, our results do not change. When we exclude the seven cases of intervention on the side of the government, expectations of rival intervention are still statistically significant with the expected impact on duration.
} 


\section{Nonrival Intervention}

One of the challenges we face is to isolate the impact of rival vs. nonrival state on the war's duration. We attempt to tackle this problem by controlling for cases where nonrival states intervened alone. If we find that interventions by nonrivals alone have a smaller impact than the "mixed" and "pure" interventions together, this will suggest that rivals are likely to be the ones contributing to the war's length. We use a dummy variable to separately code cases of rival and nonrival intervention. Cases with nonrival intervention are coded as one and cases with rival and nonrival intervention together or rival intervention alone are coded as zero.

\section{Transparency}

To assess the degree of information availability and openness in a state, we relied on Van Belle (2000) data on press freedom. The data set codes states from the most open, a value of one, to most repressed, a value of four.

\section{Expectations of different types of intervention}

We rely on multinomial logit ${ }^{15}$ to calculate predicted probabilities as proxies for expectations of rival's military, economic, and mixed interventions. ${ }^{16}$ We used Regan's (2002) data for types of intervention.

\section{Expectations $x$ (1/Time)}

The impact of expectations that are formed ex ante will wane through time unless new information arrives. To capture the impact of time, we generated a variable time $=1 / \mathrm{t}$. We interacted expectations with $1 / \mathrm{t}$ for each civil war case where expectations were formed but no intervention occurred. Multiplying expectations with $1 / \mathrm{t}$ decreases the impact of expectations exponentially each year unless new information appears. For all cases where intervention was present, we coded the time variable for the year of intervention as one to show that information is updated at that specific year. Given the updated information, time element for the years after intervention was coded as two, three, etc., with each passing year until another intervention occurred in which case it was coded as one again. For these observations, expectations were similarly interacted with $1 /$ t.

\section{Ethnicity}

Ethnic diversity can favor rebel recruitment if the level of fractionalization is not too high and thus ensures group cohesion (Collier, Hoeffler, and Söderbom, 2001; Elbadawi and Sambanis, 2000). We expect ethnically

\footnotetext{
${ }^{15}$ Given that multinomial logit analysis assumes independence of alternatives, we also checked our results with the multinomial probit model. The estimated coefficients were similar and the covariances among the error terms were statistically insignificant showing that using multinomial logit method is justified here.

${ }^{16}$ Results are listed in Appendix 2.
} 
diverse societies to provide a steady base of opposition supporters who will increase rebel resolve and lower the chances of conflict termination. We used Roeder's (2000) data on ethnolinguisitic fractionalization.

\section{Resource Finances}

Access to natural resources, such as diamonds and timber, as well as funds from drugs have been linked to rebel activity and associated with some of the longest civil wars (Fearon, 2002; Ross, 2003). We relied on Fearon's (2002) data on contraband finances and on CIA Fact Book 2004 for information on timber and diamond extraction.

\section{Coups}

Sometimes demands for transformations in the political sphere might trigger civil wars. Although these phenomena often transform the state's internal structure, they create favorable conditions for quick termination of violence (Fearon, 2002). We obtained information about coups from Fearon (2002).

\section{Regional Instability}

Fighters penetrating states' border or radicalized politics sweeping throughout the regions can trigger violence and prevent conflict resolution (Brown, 1996). Consequently, we should expect that civil wars in politically unstable regions would create conducive conditions for prolonged insurgency. We assigned a value of one to a civil war if one of the state's neighbors experienced either internal or external conflict at any point throughout the war and a value of zero for absence of such violence.

\section{Dependent Variables}

Civil war duration, measured in years, is the dependent variable in the first model. We have two time varying covariates in our first model, and thus we report the observations on a yearly basis to reflect the changing impact of the time varying covariates on the survival time. The model includes 812 observations. Civil war duration, measured in days is the unit of analysis in the second model, which yields a total of 103 observations and excludes time-varying covariates.

\section{Discussion of Results}

Table 3 reports the results from the duration analysis. Our first model includes the analysis of expectations under different conditions, such as levels of transparency in the society and the impact of time. Model two differentiates between expectations formed for various types of rival interventions, such as military and economic. Our discussion here focuses 


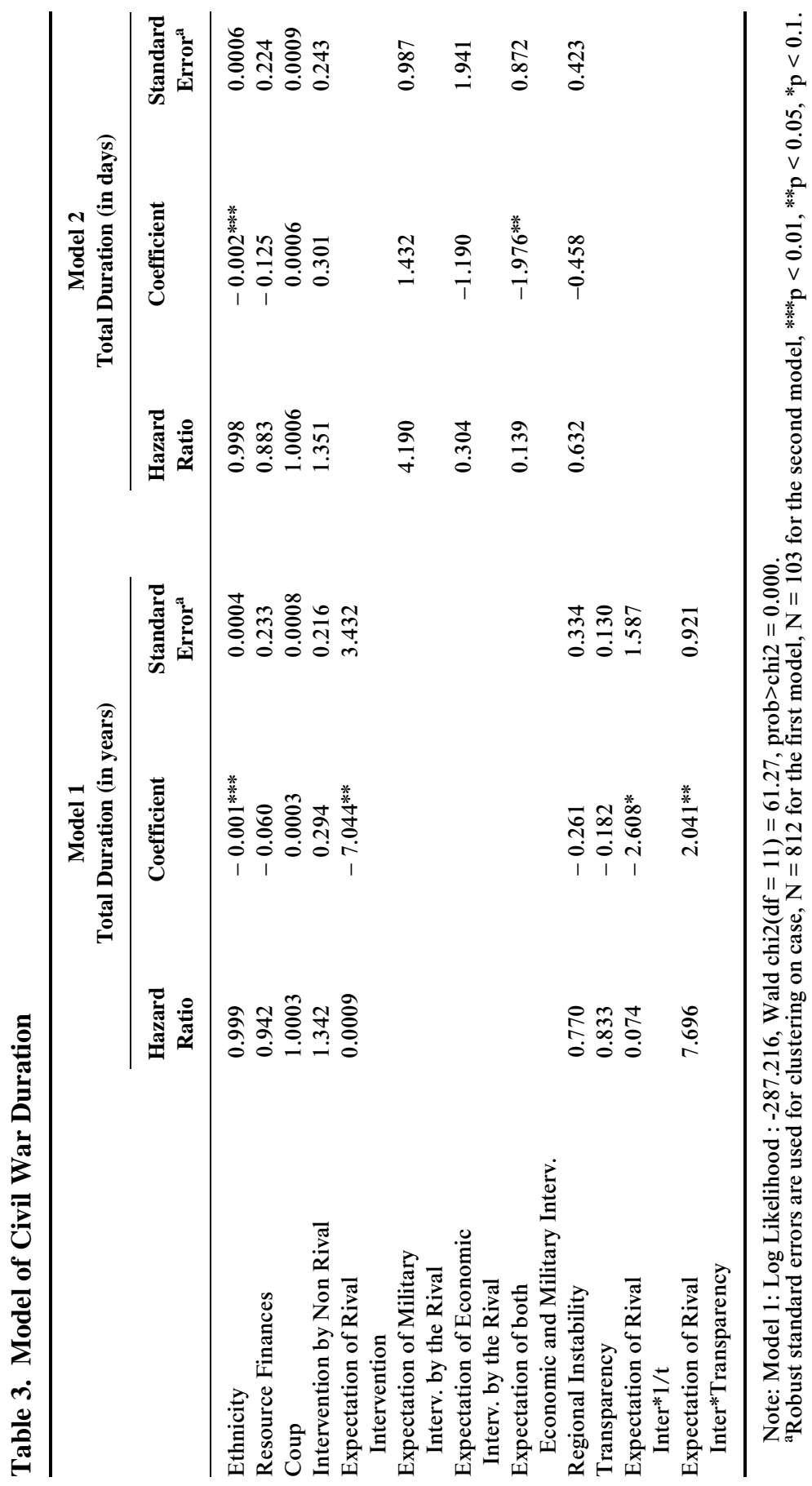


on the two models' predictions in relation to our hypotheses rather than on separate explanations for each model.

The first model shows strong support for the first two hypotheses. Expectations of rival intervention decrease the hazard rate significantly and prolong the war's duration. As expectations increase so does the propensity to fight that, in turn, is associated with longer wars. The graph below compares survival time of expectations at different values $(0.8$ and 0.5 ) and the impact of nonrival intervention when all other variables are set at their means. We can see that changes in expectations' value dramatically alter the war's duration with a much greater impact than nonrival intervention alone. For example, at approximately the twenty-first year of the conflict, there is a 20 percent chance that the war will continue when nonrival states intervene. On the other hand, we can see that probability of prolonged fighting increases significantly to 0.75 when expectations of rival intervention are set at 0.5 level.

Results also show that nonrival intervention is associated with shorter wars-the expected direction, though the variable is not statistically significant. This finding suggests that unique types of interveners contribute differently to the war's duration. When we isolated interventions by nonrival state(s) from those of rival and nonrival states together, we see that probability of conflict settlement is greater when the rival state is not involved.

Model two confirms the importance of free society in forming accurate expectations. We can see that when expectations are high and formed in a

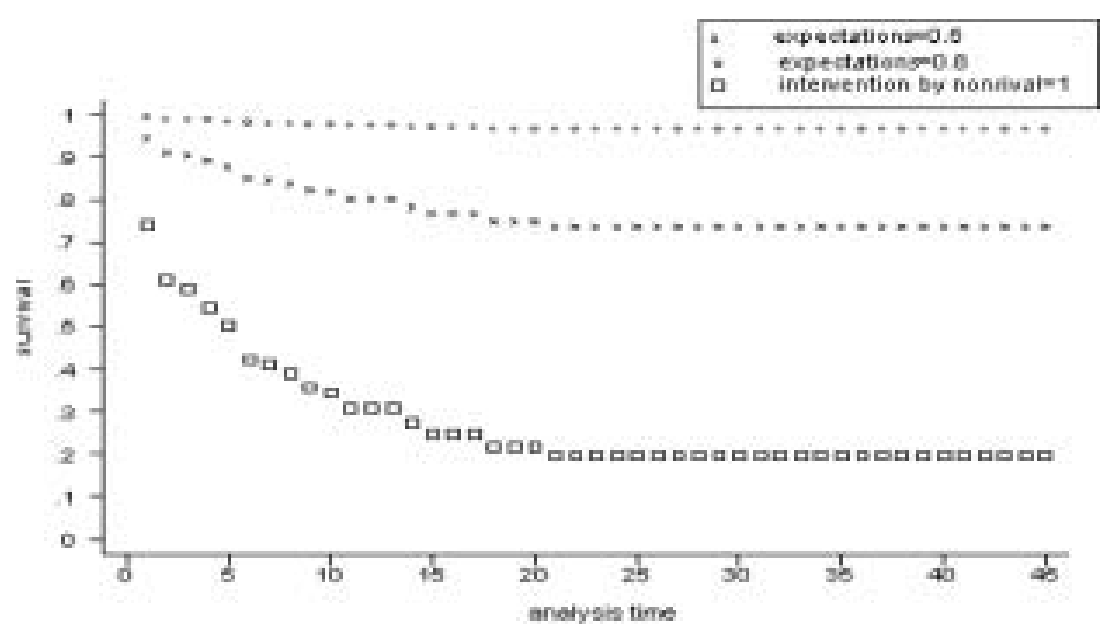

Graph 1. Survival Function: Expectations of Rival Intervention and Nonrival Intervention. 
transparent society, the propensity for fighting is greater. On the contrary, in a nontransparent environment rebels might lose their motivation to fight when they lack information to form and update expectations about intervention. This finding supports Hypothesis three. ${ }^{17}$

Model one also demonstrates how time affects expectations and, in turn, the duration of war. We find that expectations are the greatest during the initial stages of conflict when intervention might be anticipated. As time passes, the impact of expectations declines unless an intervention occurs somewhere in the middle of the conflict, at which point, expectations are updated and conflict is prolonged.

We can also see how expectations of different types of rival aid affect duration. Model two shows mixed support for Hypotheses five. While we see that expectation of military aid leads to shorter wars, the variable is not statistically significant. In the same manner, expectations of economic aid decrease the hazard rate as expected, but here again the results are not significant. It appears that differentiating between expectations of different types of aid matters less than the amount that is granted. Our results demonstrate that expectations of both military and economic aid, which implies a large form of intervention, are associated with increased rebel resolve and longer wars.

We have shown support for most of our hypotheses and demonstrated the impact of expectations of rival intervention on war duration. We can now form a more general picture of how expectations evolve and relate to civil war duration. For example, when expectations of rival intervention are set at 0.6 in the second year of the civil war in a nontransparent society, the relative risk ${ }^{18}$ of settlement is 49 percent lower than when expectations are set at $0.2 .{ }^{19}$ On the other hand, when the state has the greatest transparency level, expectations are set at 0.6 and the war is in its second year, the relative risk of settlement decreases significantly to 0.05 percent. Finally, expectations set at 0.6 in a non-transparent state at the eighth year of civil war increase the relative risk of settlement to 82 percent. We can

\footnotetext{
${ }^{17}$ One of the problems with the above result is the high level of multicollinearity with expectations variable alone and the interactive term, expectations * transparency. In the presence of multicollinearity, the standard errors might be biased and coefficients sensitive to the inclusion/exclusion of variables in the analysis. Despite this problem, we find that our interactive term and the expectations variable are statistically significant. We also find that excluding the interactive term from the model still provides an estimated hazard rate for expectations that is less than one. Consequently, we can conclude that given statistically significant results in the presence of multicollinearity, our inference is reliable.

${ }^{18}$ Relative risk implies comparison to the risk of settlement when all variables are set at their mean level.

${ }^{19}$ Other variables are set at their mean.
} 
see that unless intervention occurs, the impact of expectations decreases through time. ${ }^{20}$

\section{CONCLUSION}

Theoretically, the argument and analyses advanced in this paper make an important contribution to the studies of civil war duration and interstate dynamics. We have shown that civil conflict might be altered depending not only on the timing or target of intervention, as previous research has shown (Regan, 2003; Bach-Lindsay and Enterline, 2000), but also on the identity of the intervening state and ways in which that identity affects a desire of guerrilla forces to sustain the fight. Interstate rivals, we have argued, not only play a role in interstate violence but as intervening states, they have a profound impact on intrastate developments. Our findings demonstrate that when a civil war country is involved in a rivalry with another state, the rebels' expectations of aid will increase their desire to fight and prolong the war even before the occurrence of an interventiona dynamic that shows how a nonevent can actually alter the duration of conflict.

Specifically, we find that enduring and intense rivalries are more likely to send a credible signal to the rebels that intervention is possible altering rebel calculations and a decision whether to continue the fight. Unlike other actors, rivals have a strategic interest in prolonging the war and destabilizing their enemy. Their intense history of long militarized disputes provides a strong foundation on which rebels can form expectations of intervention. Further, since domestic audience costs associated with a policy of intervention into the enemy's affairs are much smaller for rival than nonrival states, rivals can aid the rebels for many years and prolong the war with relative ease.

Moreover, findings in this paper provide important implications for policymakers. The analysis shows that whenever intervention involves a rival, we can expect longer conflicts, particularly if the level of rivalry is both intense and enduring and if the rival itself is free from heavy constraints imposed by other rivalries. Thus, focusing on rivalries helps us understand not only dyadic interstate behavior, but also ways in which

\footnotetext{
${ }^{20}$ Turning to the control variables, we find mixed support for the existing findings on civil war duration. Only the extent of ethnic diversity in a society is statistically significant in prolonging wars. Lack of support for the impact of resources is particularly surprising given research that associates some of the longest wars with rebel ability to access funds from diamonds. The difference in our results is probably due to the types of indicators we used to code the variable-we employ a broader definition of lootable resources than previous studies (for example Fearon, 2002).
} 
international actors shape expectations of domestic groups engaged in internal violence.

Future research in this area should focus on two issues. First, analysis should explore conditions under which governments of civil war countries form expectations of interventions on their side. We have analyzed how certain rival characteristics and levels of transparency in the state can increase rebel expectations of aid and prolong fighting. Yet we have not investigated how government's expectations of aid to its own cause or to the cause of the rebels might alter government calculations about conflict settlement. Second, future studies should capture a more dynamic nature of expectations by analyzing how changes in expectations decrease the length of the war. In our paper, expectations are captured for the entire war period and only updated with the occurrence of an intervention. Yet we have no precise way of capturing how expectations vary, for example, on monthly basis. Incorporating such changes would allow us to see how propensity for settlement might change throughout the conflict.

\section{REFERENCES}

Bach-Lindsay, Dylan and Andrew J. Enterline (2000). "Killing Time: The World Politics of Civil War Duration, 1820-1992." International Studies Quarterly, Vol. 44, No. 4, pp. 615-642.

Box-Steffensmeier, Janet M. and Bradford S. Jones (2003). Timing and Political Change: Event History Modeling in Political Science, Ann Arbor: University of Michigan.

Brown, Michael (1996). "The Causes and Regional Dimensions of Internal Conflict," In Michael Brown, ed., The International Dimensions of Internal Conflict, Cambridge, MA: the MIT Press, pp. 579-580.

CIA World Fact Book, http:/ /www.cia.gov/cia/publications/factbook/, February 2004.

Collier, Paul and Anke Hoeffler (2000). "Greed and Grievance in Civil War,” Typescript. World Bank.

Collier, Paul, Anke Hoeffler, and Mans Söderbom (2001). "On the Duration of Civil War," World Bank Paper.

D’Este, Carlo. (2004). "Rising '44': Betraying Warsaw.” The New York Times, July 24.

Diehl, Paul and Gary Goertz (2000). War and Peace in International Rivalry, Ann Arbor: University of Michigan Press.

Elbadawi, Ibrahim and Nicholas Sambanis (2000). "External Interventions and the Duration of Civil Wars," World Bank Paper.

Fearon, James D. (2002). "Why Do Some Civil Wars Last So Much Longer Than Others?" Working Paper.

Kaufmann, Chaim (1996). "Possible and Impossible Solutions to Ethnic Civil Wars.” International Security, Vol. 20, pp. 136-175. 
Leblang, David (2002). "Political Uncertainty and Speculative Attacks," In Steve Chan and James Scarritt, eds., Coping with Globalization: Cross-National Patterns in Domestic Governance and Policy Performance, London: Frank Cass.

Licklider, Roy (1993). "What Have We Learned and Where Do We Go From Here?”. In Roy Licklider, ed., Stopping the Killing: How Civil Wars End, New York: New York University Press.

Mason, T. David, P. Weingarten Joseph, and Patrick J. Fett (1999). "Win, Lose, or Draw: Predicting the Outcome of Civil Wars." Political Research Quarterly, Vol. 52, No. 2, pp. 239-268.

Pearson, Frederick S. (1974). "Foreign Military Intervention and Domestic Disputes.” International Studies Quarterly, Vol. 18, No. 3, pp. 259-290.

Pruier, Gérard (1995). The Rwanda Crisis: History of a Genocide, London: C. Hurst and Company.

Regan, Patrick M. (1988). "Choosing to Intervene: Outside Interventions in Internal Conflict." The Journal of Politics, Vol. 6, No. 3, pp. 754-779.

Regan, Patrick M. (2000). Civil Wars and Foreign Powers: Outside Intervention in Intrastate Conflict, Ann Arbor: University of Michigan Press.

Regan, Patrick M. (2002). "Third-Party Interventions and the Duration of Intrastate Conflicts.” Journal of Conflict Resolution, Vol. 46, No. 1, pp. 55-73.

Regan, Patrick M. and Rodwan Abouharb (2002). "Interventions in Civil Conflicts: Tools of Conflict Management or Simply Another Participant?” World Affairs.

Rasler, Karen (1983). "Internationalized Civil War: A Dynamic Analysis of the Syrian Intervention in Lebanon." Journal of Conflict Resolution, Vol. 27, No. 3, September, pp. 421-456.

Roeder, Philip G. Ethnolinguistic Fractionalization (ELF) Indices, 1961 and 1985 http://weber.ucsd.edu $\backslash \sim$ proeder $\backslash$ elf.htm, January 10, 2004.

Ross, Michael (2003). "Oil, Drugs, and Diamonds: How Do Natural Resources Vary in Their Impact of Civil War." In Karen Ballentine and Jake Sherman, eds., Beyond Greed and Grievances: the Political Economy of Armed Conflict.

Schofield, Victoria (2003). Kashmiri in Conflict, New York: Tauris.

Schultz, K.A. (1999). "Do Democratic Institutions Constrain or Inform? Contrasting Two Institutional Perspectives on Democracy and War." International Organization, Vol. 53, No. 2, pp. 233-266.

Snidal, Duncan (1993). "Relative Gains and the Pattern of International cooperation" in David A. Baldwin (ed.) Neorealism and Neoliberalism: the Contempary Debate. New York: Colombia University Press.

Van Belle, Douglas A. (2000). Press Freedom and Global Politics, Westport: Praeger.

Walter, Barbara F. (1997). "The Critical Barrier to Civil War Settlement." International Organization, Vol. 51, No. 3, Summer, pp. 335-364.

Walter, Barbara F. and Jack Snyder (eds.) (1999). Civil Wars, Insecurity, and Intervention. New York: Colombia University Press.

Walter, Barbara F. (2002). Committing to Peace: The Successful Settlement of Civil Wars, Princeton: Princeton University Press.

Winkler,Bernhard (2002). "Which Kind of Transparency? On the Need for Effective Communication in Monetary Policy-Making," Working Paper.

Wirsing, Robert G. (1994). India, Pakistan, and the Kashmir Dispute: On Regional Conflict and Its Resolution, New York: St. Martin's Press. 
Appendix 1. Civil Wars Coinciding with Rivalries (1944-1992).

Civil War Rival(s)

1. Greece (1944-49) Bulgaria (I)*, Albania (I)

2. China (1946-50) former USSR, Japan, France, Mongolia

3. Burma (1948-ongoing) China (I), Thailand, Taiwan

4. India (1954-64) China, Pakistan, Portugal

5. Indonesia (1956-60) Netherlands

6. China (1959-ongoing) USA, former USSR, India, S. Korea, UK, Burma, Thailand, Laos,

N. Vietnam, S. Vietnam, Philippines, Australia, New Zealand, Taiwan, Nepal

7. Ethiopia (1960-91) Sudan (I), Somalia (I)

8. S.Vietnam (1960-65) China, Cambodia

9. Zaire (1960-65) Congo Brazzaville

10. Laos (1960-62) Thailand, former USSR (I), Vietnam

11. Iraq (1961-66) UK, Iran, Turkey

12. Yemen (1962-67) Saudi Arabia (I), UK

13. Laos (1963-73) Thailand, N. Vietnam (I), China

14. Sudan (1963-72) Uganda

15. Indonesia (1963-ongoing) Japan, UK, Papua New Guinea

16. Israel (1964-ongoing) Iraq, Egypt, Syria, Jordan, Lebanon, former USSR, Algeria

17. Thailand (1965-85) Laos, Cambodia, N. Vietnam, Burma, China (I)

18. Zaire (1967) Congo Brazzaville

19. Spain (1968-ongoing) Morocco, Iran

20. UK (1969-ongoing) former USSR, Iraq, Syria, Guatemala Argentina, Iran

21. Cambodia (1970-75) Thailand, USA (I), Vietnam (I)

22. Jordan (1970) Israel, Syria (I), Iraq

23. South Africa (1970-ongoing) Swaziland, Romania, Zimbabwe

24. Uganda (1971-72) Sudan, Romania

25. Bangladesh (1971-ongoing) India

26. Pakistan (1971) Afghanistan, India (I)

27. Guatemala (1972-ongoing) Mexico, UK

28. Philippines (1972-ongoing) Malaysia

29. Zimbabwe (1972-79) Romania

30. Pakistan (1973-77) Afghanistan (I), India

31. Iraq (1974-75) UK, Israel, Kuwait

32. Cyprus (1974) Turkey (I)

33. Angola (1975-91) France, Morocco

34. Mauritania (1975-ongoing) Senegal, Romania

35. Morocco (1975-ongoing) Cuba, Algeria (I), Angola

36. Zaire (1977) Congo Brazzaville, Cuba

37. Zaire (1978-79) Congo Brazzaville

38. Afghanistan (1978-92) Iran (I), USSR (I), Pakistan (I)

39. Chad (1978-82) Romania

40. Iran (1978-79) former USSR, Iraq (I)

41. Nicaragua (1978-79) Costa Rica

42. Cambodia (1978-91) Thailand (I)

43. El Salvador (1979-92) Honduras (I)

44. Mozambique (1979-92) Romania

(Continued) 


\section{Appendix 1. (Continued)}

Civil War Rival(s)

45. Uganda (1980-88) Kenya, Zaire

46. Zimbabwe (1980-88) South Africa (I)

47. Iran (1981-82) former USSR, Iraq, Kuwait, Afghanistan

48. Peru (1982-ongoing) USA (I)

49. Sri Lanka (1982-ongoing) India (I)

50. Nicaragua (1982-90) Costa Rica, Honduras (I), USA

51. Somalia (1982-91) Ethiopia (I)

52. Sudan (1983-ongoing) Ethiopia, Libya (I)

53. Chad (1983-86) Romania

54. Colombia (1984-ongoing) Venezuela

55. Turkey (1984-ongoing) Cyprus, Greece, Iran, Bulgaria

56. Iraq (1985-ongoing) UK (I), Iran (I), Israel, Kuwait, Syria, Spain (I), Italy (I), Malta, Norway (I), Bahrain, Australia (I), Panama, France (I), Greece (I), Cyprus, Liberia, Turkey (I), USA (I)

57. Ecuador (1985-89) Peru

58. India (1985-ongoing) Sri Lanka, China, Pakistan (I), Bangladesh

59. Papua New Guinea (1988-91) Indonesia

60. Romania (1989) Congo, Russia

*(I) indicates intervention. 


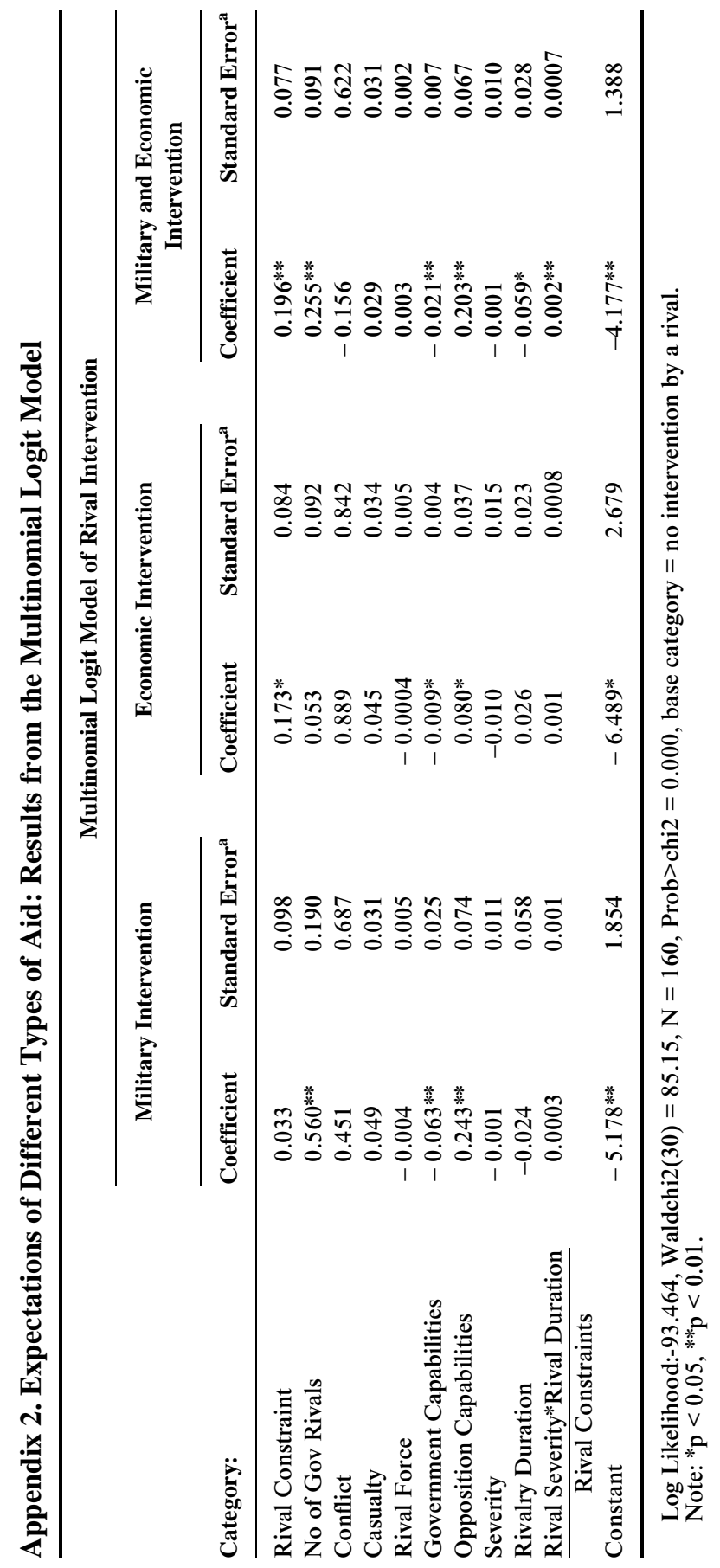


Copyright of International Interactions is the property of Routledge, Ltd. and its content may not be copied or emailed to multiple sites or posted to a listserv without the copyright holder's express written permission. However, users may print, download, or email articles for individual use. 